\title{
LONG-TERM CHANGES IN BODY BUILD OF MALE AND FEMALE JUDO COMPETITORS
}

\author{
Jadwiga Pietraszewska, ${ }^{A, B, C, D}$ Anna Burdukiewicz, ${ }^{B, D}$ Aleksandra Stachoń,,, D \\ Justyna Andrzejewska, ${ }^{\mathrm{B}, \mathrm{D}}$ Krystyna Chromik ${ }^{\mathrm{B}, \mathrm{D}}$ \\ Department of Physical Anthropology, University of Physical Education in Wrocław, Poland

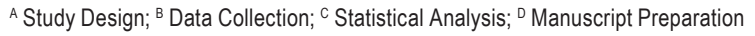 \\ Address for correspondence: \\ Jadwiga Pietraszewska \\ Department of Physical Anthropology \\ Faculty of Sport Studies \\ University of Physical Education in Wrocław \\ Al. Paderewskiego 35, P-2, 61-512 Wrocław, Poland \\ E-mail: jadwiga.pietraszewska@awf.wroc.pl
}

\begin{abstract}
Ahstract The aim of the study was to determine if changes in the body build of judo athletes over a time span of 20 years are in line with trends described in the literature. Anthropometry of 60 male and 46 female judokas was performed. Data was collected from two cohorts: the first involved 30 males and 23 females measured in 1994-1995 and the second 30 males and 23 females in 2013. Anthropometric profiles included measurements of skinfolds, height, weight, and body and segment lengths, breadths, and girths. Although relatively identical heights and weights were found between the cohorts, significant differences were detected for body proportion measures. Males in 1994-1995 showed a significantly longer trunk, wider shoulders and hips, and more subcutaneous adipose tissue than the 2013 cohort. Females in 1994-1995 showed a shorter trunk, larger diameters of the trunk in relation to body height, and significantly lower skinfold thicknesses than the 2013 cohort. The direction of changes in the physical characteristics of judokas should be taken into consideration by coaches during training. Combat techniques should be adapted to the morphological traits of the athletes to achieve success and minimize the risk of overloading or injury.
\end{abstract}

Key Worlds secular trend, judo, body proportion

\section{Introduction}

Secular changes in human beings are indicative of how the body develops in light of genetic determinants (Tanner, 1992; Bielicki, Szklarska, 1999). According to Henneberg (2001), these changes are the result of factors that affect gene expression responsible for growth. Significant factors include healthcare, diet, the state of livestock farming and agriculture, all of which may stimulate the endocrine system to secrete growth hormones. The literature most commonly indicate secular trends in increased body height and reduced age of sexual maturation (Roche, 1979; Tanner, 1987; Malina, 1990; Hauspie, Vercauteren, Susanne, 1997; Bielicki, Szklarska, 1999; Cole, 2000). 
However, change in the relationship between body height and weight was found to vary in different ways depending on socioeconomic criteria. Some studies have found a plateauing or even reversal of such secular changes in certain populations, mostly among those with relatively stable, high-level living conditions (Brundtland, Walloe, 1973; Cernerud, Lindgren, 1991).

The findings of many studies have also indicated intergenerational changes in body composition, subcutaneous fat levels, body proportions, and somatotype (Piechaczek, Lewandowski, Orlicz, 1996; Hughes, Li, Chinn, Rona, 1997; Ziółkowska-Łajp,1999; Stachoń, Burdukiewicz, Pietraszewska, Andrzejewska, 2012; Saczuk, Wasiluk, Wilczewski, Wilczewski, 2016). In Poland, a number of studies identifying secular trends in body build have focused on populations of university students representing academic disciplines (Milicer, Skibińska, Skład, 1974; Pilicz, 1979; Piechaczek, Łaska-Mierzejewska, Skibińska, 1986; Pilicz, 1998; Sitek, Szkudlarek, Antoszewski, 2007; Mleczko, Januszewski, 2009; Stachoń et al., 2012). Differences in the level of changes have been identified between males and females, what can be conditioned by varied susceptibility to environmental stimuli (Bielicki, Charzewski, 1977; Chlebicka, 1988).

While the above studies have examined untrained populations, there is not much research of study on identifying secular trends among athletes. Sedeaud et al. (2014) showed, that between 1871 and 2011, athletes from the four sports have increased significantly in mass, height and BMI. Research by Malina, Figueiredo, Coelhoe-Silva (2017) indicates, that the body size of youth soccer players increased between 1978-1999 and 2000-2015. Norton, Olds (2001) report, that athletes in many sports have been getting taller and more massive over time; the rates of rise outstripping those of the secular trend. Some sports demand a narrow range of morphological characteristics. In these sports the size of the most successful athletes has remained constant, despite the secular trend in the population non-athletes. Each sport demands a particular set of attributes, including body composition and proportions. This issue is of importance in light of the association between structural body dimensions and functional performance. Such trend analysis may contribute to current assessments of the body's response to exercise and also aid athletes. In certain athletic disciplines, talent identification and athlete selection is also based on an anthropometric profile that may need to be modified due to changes in the physical characteristics of successive generations of athletes. Furthermore, developments in specialized training programs should take changes in body build in order to minimize injury via overloading.

The purpose of the present study was to examine the changes in the body build of judo athletes and, if present, determine whether they were in line with the trends observed in recent decades in untrained groups and other sport disciplines. In order to achieve that purpose, the following research questions were posed:

- Is the course of secular changes the same in judokas of both sexes?

- Which features of the somatic build exhibit the most significant changes?

- Are secular changes in judokas the same as in other populations?

The study also considered whether changes in body build may have had an effect on muscle strength.

\section{Material and methods}

\section{Participants}

The study used a data set of anthropometric measures on 60 male and 46 female judo practitioners from university-level sports clubs. They represented regional and national level. Data of the first group (30 men and 23 females) was collected in 1994-1995, whereas for the remaining 30 males and 23 females in 2013. 
The average age of male subjects in the first group was $21.5 \pm 2.7$ years, while in the second group it was $22.4 \pm 2.9$ years. In the group of female subjects examined in 1994-1995 the average age was $21.7 \pm 2.4$ years, while in the second group $-21.9 \pm 2.6$ years. The overall length of time that the male and female athletes had spent practising their discipline was $7-16$ years.

The male subjects represented weight categories from 66 to $90 \mathrm{~kg}$ and the female subjects - from 52 to $78 \mathrm{~kg}$. In the cohorts examined in 1994-1995 and in 2013 the share of the representatives of each weight category was the same.

\section{Measurements}

Measurements were administered according to International Standards for Anthropometric Assessment (ISAK) (Norton, Olds, 2002). They were supplemented by a few measurements. Anthropometric measures selected for analysis included: body height (B-v), trunk length (sst-sy), upper limb length (a-da3), lower limb length (B-tro), biacromial diameter (a-a), chest diameter (thl-thl), chest depth (xi-ths), biliocristal diameter (ic-ic), elbow breadth (cl-cm), knee breath (epl-epm), shoulder circumference, chest circumference at rest and at peak inhalation and exhalation, waist circumference, arm circumference at rest and flexed, hip circumference, and maximal circumferences of the forearm, thigh, and calf. A Harpenden body fat caliper was used to obtain skinfold measurements at the subscapular, triceps, forearm, suprailiac, abdominal, and medial calf regions. The measurements were made by the same people. Body height, lengths and breadths were measured to the nearest $0.1 \mathrm{~cm}$ with the use of a GPM Anthropological Instruments (SiberHegner Machinery Ltd., UK). Skinfold thickness was measured with a Tanner/Whitehouse skinfold calliper (Holtain, UK) with $0.2 \mathrm{~mm}$ graduation. Body mass was measured with an electronic weighing scale with an accuracy of $0.1 \mathrm{~kg}$. Somatotype was classified according to Sheldon's method as modified by Heath and Carter to determine the levels of endomorphy, mesomorphy, and ectomorphy in the cohorts (Carter, Heath, 1990). Body proportions were calculated based on the following ratios: trunk length/body height, biliocristal diameter/biacromial diameter, biacromial diameter/body height, biliocristal diameter/body height, chest circumference at rest/body height, chest depth/chest diameter, waist circumference/hip circumference (WHR), and BMI. Muscle strength was assessed with a Takei handgrip dynamometer. The handgrip was adjustable and measured force from 0 to $100 \mathrm{kgf}$ with an accuracy of $0.5 \mathrm{kgf}$.

\section{Statistical analysis}

Basic statistical methods included the Kolmogorov-Smirnov test to determine the normality of the data, finding it did not significantly deviate from a normal distribution. On this basis, all subsequent statistical methods assumed a normal distribution. Intergroup differences were assessed using Student's $t$ test. The strength of associations between handgrip strength and the anthropometric measures were determined by the Pearson product-moment correlation coefficient. The results obtained were analysed with the use of basic statistical methods (Statistica 12.0).

\section{Ethical apppoval}

Ethical approval for the project was obtained from the Ethical Committee at the University School of Physical Education in Wrocław (Ethical clearance 23.10.12). Their ethical guidelines were honoured throughout the study. Participants provided oral informed consent prior to testing. 


\section{Results}

No differences in body height were found between the male and female judokas from the two cohorts (Table 1). The male judokas in 1994-1995 had a significantly longer torso and wider shoulders and hips than the 2013 cohort. Among the circumference measures, significant differences were observed for arm circumference (Table 2). The 2013 male cohort had approximately $1.5 \mathrm{~cm}$ larger arm circumferences at rest and when flexed. Among the females, no statistically significant differences were noted except for shoulder circumference. The 2013 female cohort were measured with more than $4 \mathrm{~cm}$ smaller shoulder circumferences than their peers from 1994-1995.

Tahle 1. Statistical characteristics of body height, body mass, length and width of the examined competitors (mean $\pm s d$ )

\begin{tabular}{lcccc} 
& \multicolumn{3}{c}{ Males } & \multicolumn{2}{c}{ Females } \\
\cline { 2 - 5 } & 1994 & 2013 & 1994 & 2013 \\
\hline B-v (cm) & $176.8 \pm 4.09$ & $176.4 \pm 6.18$ & $166.4 \pm 6.74$ & $166.6 \pm 6.33$ \\
Body mass (kg) & $76.1 \pm 4.48$ & $77.6 \pm 4.62$ & $63.7 \pm 7.34$ & $65.8 \pm 8.85$ \\
sst-sy (cm) & $52.3 \pm 2.72^{*}$ & $50.7 \pm 2.13^{*}$ & $46.4 \pm 3.45$ & $47.8 \pm 3.42$ \\
a-da3 (cm) & $77.0 \pm 2.49$ & $77.7 \pm 3.07$ & $72.0 \pm 2.98$ & $72.6 \pm 2.42$ \\
B-tro (cm) & $93.4 \pm 3.29$ & $93.8 \pm 2.87$ & $88.7 \pm 3.49$ & $87.7 \pm 4.32$ \\
a-a (cm) & $44.5 \pm 3.12^{*}$ & $43.1 \pm 1.64^{*}$ & $38.2 \pm 2.75$ & $37.0 \pm 2.05$ \\
thl-thl (cm) & $30.6 \pm 2.67$ & $30.4 \pm 1.49$ & $26.4 \pm 1.64$ & $26.3 \pm 1.67$ \\
xi-ths (cm) & $20.6 \pm 1.36$ & $20.4 \pm 1.85$ & $18.4 \pm 1.37$ & $18.8 \pm 1.48$ \\
ic-ic (cm) & $29.6 \pm 2.47^{*}$ & $28.3 \pm 1.19^{*}$ & $28.9 \pm 2.11$ & $27.8 \pm 2.27$ \\
cl-cm (cm) & $7.2 \pm 0.30$ & $7.2 \pm 0.26$ & $6.3 \pm 0.35$ & $6.3 \pm 0.35$ \\
epl-epm (cm) & $10.1 \pm 0.42$ & $10.2 \pm 0.37$ & $9.4 \pm 0.53$ & $9.4 \pm 0.60$ \\
\hline
\end{tabular}

B-v (body height), sst-sy (trunk length), a-da3 (upper limb length), B-tro (lower limb length), a-a (biacromial diameter), thl-thl (chest diameter), xi-ths (chest depth), ic-ic (biiliocristal diameter), cl-cm (elbow breadth), epl-epm (knee breath).

"Significant differences between groups (1994 and 2013) ( $p \leq 0.05)$.

Table 2. Statistical characteristics of circumference of the examined competitors (mean $\pm \mathrm{sd}$ )

\begin{tabular}{lcccc} 
& \multicolumn{2}{c}{ Males } & \multicolumn{2}{c}{ Females } \\
\cline { 2 - 5 } & 1994 & 2013 & 1994 & 2013 \\
\hline Shoulder circumference $(\mathrm{cm})$ & $118.6 \pm 4.10$ & $118.7 \pm 4.23$ & $110.2 \pm 6.61^{*}$ & $105.8 \pm 6.24^{*}$ \\
Chest circumference at rest $(\mathrm{cm})$ & $100.6 \pm 5.10$ & $99.9 \pm 4.69$ & $91.0 \pm 5.07$ & $90.8 \pm 4.13$ \\
Chest circ. at peak inhalation $(\mathrm{cm})$ & $105.2 \pm 4.76$ & $104.1 \pm 4.38$ & $96.1 \pm 5.02$ & $95.2 \pm 4.55$ \\
Chest circ. at peak exhalation $(\mathrm{cm})$ & $97.1 \pm 4.16$ & $97.3 \pm 5.03$ & $88.8 \pm 5.52$ & $88.0 \pm 4.70$ \\
Waist circumference $(\mathrm{cm})$ & $78.5 \pm 3.98$ & $80.2 \pm 4.26$ & $72.4 \pm 5.54$ & $74.5 \pm 5.60$ \\
Arm circumference $(\mathrm{rest})(\mathrm{cm})$ & $31.4 \pm 2.12^{*}$ & $33.0 \pm 1.99^{*}$ & $27.9 \pm 2.46$ & $28.8 \pm 2.50$ \\
Arm circumference $($ flexed) $(\mathrm{cm})$ & $34.9 \pm 1.98^{*}$ & $36.5 \pm 2.21^{*}$ & $30.5 \pm 2.33$ & $31.0 \pm 2.23$ \\
Forearm circumferences $(\mathrm{max})(\mathrm{cm})$ & $28.3 \pm 1.44$ & $28.5 \pm 1.48$ & $25.3 \pm 1.55$ & $25.0 \pm 1.36$ \\
Hip circumference $(\mathrm{cm})$ & $97.4 \pm 3.76$ & $96.4 \pm 4.11$ & $98.3 \pm 6.14$ & $100.4 \pm 7.10$ \\
Thigh circumference $(\mathrm{cm})$ & $57.4 \pm 2.35$ & $57.7 \pm 2.91$ & $58.3 \pm 4.71$ & $58.5 \pm 4.72$ \\
Calf circumference $(\mathrm{cm})$ & $37.1 \pm 1.68^{*}$ & $38.1 \pm 2.00^{*}$ & $36.6 \pm 3.15$ & $36.8 \pm 2.59$ \\
\hline
\end{tabular}

"Significant differences between groups (1994 and 2013) $(p \leq 0.05)$. 
Larger values of subcutaneous adipose tissue was found among the male cohorts from 1994-1995 than those in 2013. Although almost all skinfold values were larger, only triceps skinfold thickness was statistically significant (Table 3).

Table 3. Statistical characteristics of skinfolds and body build components of the examined competitors (mean $\pm \mathrm{sd}$ )

\begin{tabular}{lcccc} 
& \multicolumn{3}{c}{ Males } & \multicolumn{2}{c}{ Females } \\
\cline { 2 - 5 } & \multicolumn{1}{c}{1994} & 2013 & 1994 & 2013 \\
\hline Subscapular skinfold $(\mathrm{mm})$ & $8.8 \pm 2.70$ & $8.7 \pm 1.71$ & $10.3 \pm 3.23$ & $11.9 \pm 3.54$ \\
Triceps skinfold $(\mathrm{mm})$ & $5.6 \pm 2.28^{*}$ & $4.4 \pm 1.65^{*}$ & $4.0 \pm 1.54^{*}$ & $11.0 \pm 2.85^{*}$ \\
Forearm skinfold $(\mathrm{mm})$ & $3.3 \pm 0.93$ & $2.9 \pm 0.64$ & $2.8 \pm 0.60^{*}$ & $4.0 \pm 1.04^{*}$ \\
Suprailiac skinfold $(\mathrm{mm})$ & $8.2 \pm 3.44$ & $6.6 \pm 2.45$ & $7.6 \pm 3.18^{*}$ & $12.4 \pm 4.22^{*}$ \\
Abdominal skinfold $(\mathrm{mm})$ & $6.9 \pm 2.39$ & $8.4 \pm 3.54$ & $9.8 \pm 4.60^{*}$ & $13.8 \pm 3.73^{*}$ \\
Calf skinfold $(\mathrm{mm})$ & $4.3 \pm 1.07$ & $4.4 \pm 0.82$ & $3.2 \pm 0.95^{*}$ & $7.5 \pm 2.24^{*}$ \\
Endomorphy & $2.2 \pm 0.71^{*}$ & $1.8 \pm 0.59^{*}$ & $2.1 \pm 0.77^{*}$ & $3.6 \pm 0.85^{*}$ \\
Mesomorphy & $6.0 \pm 0.84^{*}$ & $6.6 \pm 1.04^{*}$ & $5.2 \pm 1.41$ & $5.1 \pm 0.99$ \\
Ectomorphy & $2.0 \pm 0.66$ & $1.7 \pm 0.80$ & $1.8 \pm 1.09$ & $4.0 \pm 0.94$ \\
\hline
\end{tabular}

"Significant differences between groups (1994 and 2013) $(\mathrm{p} \leq 0.05)$.

Consequently, this finding was congruent with the significantly larger proportion of endomorphy and lower share of mesomorphy in the 1994-1995 cohorts. Opposite results were found in the group of female judokas. The 2013 females showed increased skinfold thickness compared with the 1994-1995 cohort. With the exception of the subscapular skinfold, the remaining skinfold measures were significantly different between the two cohorts, the effect of which accounted for the higher level of endomorphy in the 2013 females.

When comparing body proportions, a number of significant differences were also observed (Table 4). The 1994-1995 male cohort exhibited greater biacromial and biliocristal diameters in relation to body height than their peers from 2013. In addition, they showed a relatively longer trunk and lower waist circumference/hip circumference ratio. Similar among the females, the 1994-1995 cohort had larger biacromial and biiliocristal

Table 4. Statistical characteristics of the proportion indexes of the examined competitors (mean $\pm s d$ )

\begin{tabular}{|c|c|c|c|c|}
\hline & \multirow{2}{*}{\multicolumn{2}{|c|}{ Males }} & \multirow{2}{*}{\multicolumn{2}{|c|}{ Females }} \\
\hline & & & & \\
\hline & 1994 & 2013 & 1994 & 2013 \\
\hline$($ sst-sy / B-v) × 100 & $29.6 \pm 1.18^{*}$ & $28.7 \pm 0.55^{*}$ & $27.8 \pm 1.40^{*}$ & $28.7 \pm 1.68$ \\
\hline (sst-sy / B-tro) × 100 & $56.0 \pm 2.28^{*}$ & $54.14 \pm 1.59^{*}$ & $52.3 \pm 3.62^{*}$ & $54.7 \pm 4.64$ \\
\hline (ic-ic / a-a) × 100 & $66.7 \pm 5.67$ & $65.7 \pm 3.33$ & $75.8 \pm 4.48$ & $75.3 \pm 5.12$ \\
\hline$(a-a / B-v) \times 100$ & $25.2 \pm 1.66^{*}$ & $24.4 \pm 0.85^{*}$ & $23.0 \pm 1.64^{*}$ & $22.2 \pm 0.86$ \\
\hline$($ ic-ic / B-v) × 100 & $16.8 \pm 1.36^{*}$ & $16.0 \pm 0.73^{*}$ & $17.4 \pm 1.13^{*}$ & $16.7 \pm 1.25$ \\
\hline (chest circumference / B-v) $\times 100$ & $56.9 \pm 2.99$ & $56.7 \pm 2.29$ & $54.7 \pm 3.34$ & $54.5 \pm 2.67$ \\
\hline (waist circumference $/$ hip circumference) $\times 100$ & $80.7 \pm 3.61^{*}$ & $83.2 \pm 2.55^{*}$ & $73.7 \pm 3.98$ & $74.3 \pm 5.31$ \\
\hline$(x i-t h s /$ thl-thl) $\times 100$ & $67.6 \pm 6.48$ & $67.1 \pm 5.59$ & $69.8 \pm 5.30$ & $71.4 \pm 4.39$ \\
\hline BMI & $24.3 \pm 1.41$ & $25.0 \pm 1.58$ & $23.0 \pm 2.35$ & $23.7 \pm 2.45$ \\
\hline
\end{tabular}

B-v (body height), sst-sy (trunk length), B-tro (lower limb length), a-a (biacromial diameter), thl-thl (chest diameter), xi-ths (chest depth), ic-ic (biiliocristal diameter).

'Significant differences between groups (1994 and 2013) ( $p \leq 0.05)$. 
diameters in relation to body height than the 2013 cohort. A different direction was observed in terms of female trunk length. Judokas in 2013 exhibited a longer trunk in relation to body height and lower limb length than the 1994-1995 cohort.

Table 5. Correlation of the handgrip strength with the morphological features of the examined competitors (Pearson's r)

\begin{tabular}{|c|c|c|c|c|c|}
\hline & Males & Females & & Males & Females \\
\hline Body mass (kg) & 0.45 & 0.39 & Waist circumference (cm) & 0.19 & 0.12 \\
\hline B-v (cm) & 0.28 & 0.37 & Arm circumference (rest) (cm) & 0.30 & 0.14 \\
\hline sst-sy (cm) & 0.25 & 0.27 & Arm circumference (flexed) $(\mathrm{cm})$ & 0.42 & 0.11 \\
\hline B-tro (cm) & 0.27 & 0.20 & Forearm circumferences $(\mathrm{cm})$ & 0.69 & 0.26 \\
\hline a-a (cm) & 0.20 & 0.31 & Hip circumference (cm) & -0.06 & 0.27 \\
\hline thl-thl (cm) & -0.04 & 0.16 & Thigh circumference $(\mathrm{cm})$ & 0.21 & 0.07 \\
\hline xi-ths (cm) & 0.13 & 0.02 & Calf circumference $(\mathrm{cm})$ & 0.47 & 0.30 \\
\hline ic-ic (cm) & 0.02 & 0.12 & Subscapular skinfold (mm) & -0.31 & 0.09 \\
\hline $\mathrm{cl}-\mathrm{cm}(\mathrm{cm})$ & 0.52 & 0.23 & Triceps skinfold (mm) & -0.21 & 0.08 \\
\hline epl-epm (cm) & 0.12 & 0.29 & Suprailiac skinfold (mm) & -0.20 & 0.11 \\
\hline Shoulder circumference $(\mathrm{cm})$ & 0.33 & 0.28 & Abdominal skinfold (mm) & -0.10 & -0.03 \\
\hline Chest circumference (cm) & 0.23 & 0.33 & Calf skinfold (mm) & -0.18 & -0.22 \\
\hline
\end{tabular}

B-v (body height), sst-sy (trunk length), B-tro (lower limb length), a-a (biacromial diameter), thl-thl (chest diameter), xi-ths (chest depth), ic-ic (biiliocristal diameter), cl-cm (elbow breadth), epl-epm (knee breath).

The search for associations between handgrip strength and the anthropometric measures indicated that the strongest correlation among males was between handgrip strength and body weight, circumferences of the forearm and arm, and humerus breadth (Table 5). Among females, the strongest relationship was between handgrip strength and body weight, body height, chest circumference, and biacromial diameter.

\section{Discussion}

When analyzing for trends in body build, the majority of the literature indicates increased body height in successive generations of Polish males and females (Milicer et al. 1974; Hughes et al. 1997; Pilicz, 1998; Sitek et al. 2007; Mleczko, Januszewski, 2009; Stachoń et al. 2012). This finding was not confirmed in the samples of male and female judo practitioners from 1994-1995 and 2013, although this may have been the effect of sampling athletes from the same weight categories.

In other populations, Tanner, Hayashi, Preece, Cameron (1982) indicated a secular trend in body height due to changes in lower limb length resulting in differences in trunk /leg proportions. Compared with the present study, a similar result was found among the males in which the 2013 cohort exhibited significantly reduced trunk length in relation to body height and also to lower limb length. This is unfavorable for judokas, because the center of gravity is higher. Among females, a significant increase in the length of the trunk was found among the 2013 cohort. Various authors have suggested that the physical traits of a martial artist could be used to determine the most optimal fighting technique (Sterkowicz-Przybycień, 2010). A similar conclusion was reached by Lech, Sterkowicz, Rukasz (2007), who found that taller and thinner individuals were more likely to use leg techniques, while those larger and shorter more commonly used hand techniques. Differences were also found in the effectiveness of blocking 
depending on body height. The results of the present study indicate the validity of analyzing fighting techniques in martial arts by controlling for the physical traits of martial artists.

The literature on the Polish population describes a slimmer body profile in successive generations of young adult males (Piechaczek et al. 1996; Milicer et al. 1974; Pilicz, 1998; Mleczko, Januszewski, 2009). While the results of the present study did indicate a decrease in skeletal size (biacromial and bicristal diameters), the body profile of the males became more massive due to increased muscle mass. This was indicated by the significantly larger arm circumferences and larger waist circumference/hip circumference ratio. A significant increase of mesomorphy was also found in the 2013 cohort, in which a trend of decreased skinfold thickness and, consequently, decreased level of endomorphy can be seen. A similar trend in the level of mesomorphy was observed by Stachoń et al. (2012) among males attending a physical education university. However, none of the cited studies found any significant changes in the level of endomorphy. Low body fat content is known to assist fighting performance as well as improve blocking reaction speed, qualities that are very important in combat sports (Pieter, Bercades, Kim, 2006). Therefore, the observed differences between the generations of judokas may be indicative of suitable training methods.

Among the female judokas, a trend similar to the males was observed in the diameters of the torso. The 2013 cohort exhibited smaller shoulder and hip diameters than those from 1994-1995. While no significant changes in musculature and BMI were noted, a marked increase in skinfold thicknesses can be observed, which resulted in a significantly greater level of endomorphy. A similar trend was observed in Polish physical university students by Stachoń et al. (2012).

Research conducted on different populations has found that the trend for increased stature and earlier development did not translate into improved motor skills (Roche, 1979; Pilicz 1998; Mleczko, Januszewski, 2009; Przewęda, Dobosz, 2003; Przewęda, 2009; Drozdowski, Ziółkowska-Łajp, 2012). Due to a lack of data, long-term changes in the level of motor performance was not analyzed in the present study. However, we did search for relationships between handgrip strength and the anthropometric measures in the 2013 cohort.

Studies have shown that in judo a competitor holds an opponent by judogi (clothing) for a long time. A substantial handgrip strength is crucial in fight circumstances (Marcon, Franchini, Jardim, Neto, 2010; Vidal Andreato et al., 2011). The findings indicate that handgrip strength in males most strongly correlated with body weight and limb circumference. The observed trend of increasing limb circumference when comparing the 2013 and 1994-1995 cohorts allows for the conclusion that the strength ability of judo practitioners has increased compared with the previous generation of judokas. Other studies have confirmed the relationship between strength and the cross-sectional area of muscle (Maughan, Watson, Weir, 1983). The correlation coefficients were lower in females, with the strongest relationship between handgrip strength and the upper torso measures. This result supports the conclusion that handgrip strength in female judokas from 2013 is not directly related with changes in their body size and shape.

\section{Conclusions and Practical application}

Secular changes in body build and proportions among male and female judo practitioners were not always congruent with the trends described in the literature among various populations. This indicates the need to monitor the direction of changes separately for athletes of various disciplines. The results obtained in the study with regard to the tendency for female athletes to have more body fat should prompt trainers to modify the training regimen for women accordingly. Changes in the body proportions of judokas should be taken into consideration by coaches 
during training. Combat techniques should be adapted to the morphological traits of the athletes to achieve success and minimize the risk of overloading or injury.

\section{Conflict of interest}

The authors state no conflict of interest.

\section{References}

Bielicki, T., Charzewski, J. (1977). Sex differences in the magnitude of statural gains of offspring over parents. Human Biology, 49, 265-277.

Bielicki, T., Szklarska, A. (1999). Secular trends in stature in Poland, national and social class-specific. Annals of Human Biology, 26 (3), 251-258.

Brundtland, G.H., Walloe, L. (1973). Menarcheal age in Norway, halt in the trend towards earlier maturation. Nature, 241 (5390), 478-479.

Carter, J.E.L., Heath, B.H. (1990). Somatotyping- development and applications. Cambridge Studies in Biological Anthropology, Cambridge University Press 5.

Cernerud, J., Lindgren, G.W. (1991). Secular changes in height and weight of Stockholm schoolchildren born in 1933, 1943,1953 and 1963. Annals of Human Biology, 18 (6), 497-505.

Chlebicka, E. (1988). Analysis of changes in the development of somatic and motoric traits in academic youth examined 10 years apart [in Polish]. Przegląd Antropologiczny, 54, 175-179.

Cole, T.J. (2000). Secular trends in growth. Proceedings of the Nutrition Society, 59 (2), 317-324.

Drozdowski, M., Ziółkowska-Łajp, E. (2012). Relationships between Chosen Motor and Morphological Characteristics of Young Men and Women, Longitudinal Research. Baltic journal of health and physical activity, 4 (3), 155-163.

Hauspie, R.C., Vercauteren, M., Susanne, C. (1997). Secular changes in growth and maturation, an update. Acta Paediatrica, Suppl., $423,20-27$.

Henneberg, M. (2001). Secular trends in body height -indicator of general improvement in living conditions or of a change in specific factors? In: P. Dasgupta, R. Hauspie (eds.) Perspectives in human growth, development and maturation (pp. 159-168). Boston: Kluwer Academic Publishers.

Hughes, J.M., Li, L., Chinn, S., Rona, R.J. (1997). Trends in growth in England and Scotland, 1972 to 1994. Archives of Disease in Childhood, 76, 182-189.

Lech, G., Sterkowicz, S., Rukasz, W. (2007). Significance of body height in martial arts (as exemplified by judo fighters). Human Movement, 8 (1), 21-26.

Malina, R.M., Figueiredo, A.J., Coelho-e-Silva, M.J. (2017). Body Size of Male Youth Soccer Players: 1978-2015. Sports Medicine, 47 (10), 1983-1992.

Malina, R.M. (1990). Research on secular trends in auxology. Anthropologischer Anzeiger, 48 (3), $209-227$.

Marcon, G., Franchini ,E., Jardim, J.R., Neto, T.L.B. (2010). Structural Analysis of Action and Time in Sports: Judo. Journal of Quantitative Analysis in Sports, 6 (4), 1-13.

Maughan, R.J., Watson, J.S., Weir, J. (1983). Strength and cross-sectional area of human skeletal muscle. Journal of Physiology, 338, 37-49.

Milicer, H., Skibińska, A., Skład, M. (1974). Secular trend in body size and proportions of academic youth [in Polish]. Wychowanie Fizyczne i Sport, 4, 63-71.

Mleczko, E., Januszewski, J. (2009). Long-term trends of changes in physical and motor development observed among Cracovian students [in Polish]. Antropomotoryka, 46, 65-79.

Norton, K., Olds, T. (2001). Morphological Evolution of Athletes Over the 20th Century. Causes and Consequences. Sports Medicine, 31 (11), 763-783.

Norton, K.N., Olds, T. (2002). Anthropometrica. Sydney, Australia: UNSW Press.

Piechaczek, H., Łaska-Mierzejewska, T., Skibińska, A. (1986). Secular trend in body size in period of 35 years [in Polish]. Wychowanie Fizyczne i Sport, 4, 39-48. 
Piechaczek, H., Lewandowski, J., Orlicz, B. (1996). Changes in body build of academic youth in period of 35 years [in Polish]. Wychowanie Fizyczne i Sport, 3, 3-14.

Pieter, W., Bercades, L.T., Kim, G.D. (2006). Relative Total Body Fat And Skinfold Patterning In Filipino National Combat Sport Athletes. Journal of Sports Science \& Medicine, 5, 35-41.

Pilicz, S. (1979). Secular trend in body height and body mass of academic youth 1954-1974 [in Polish]. Zeszyt Naukowy WSI Koszalin, $6,21-25$.

Pilicz, S. (1998). Secular changes in the physical development and physical fitness of Polish students [in Polish]. Wychowanie Fizyczne i Sport, 4, 3-12.

Przewęda, R. (2009). Changes in physical fitness of Polish youth during the last three decades [in Polish]. Studia Ecologiae et Bioethicae, 7 (1), 57-71.

Przewęda, R., Dobosz, J. (2003). Physical fitness of Polish youth [in Polish]. Studia i Monografie AWF Warszawa, 98.

Roche, A.F. (1979). Secular trends in human growth, maturation and development. Monographs of the Society for Research of Child Development, 44 (3-4), 1-120.

Saczuk, J., Wasiluk, A., Wilczewski, R., Wilczewski, A. (2016). Differences in Body Build and Physical Fitness of PE Students from the Faculty of Physical Education and Sport in Biała Podlaska in the Years 1989, 2004, and 2014. Polish Journal of Sport and Tourism, 23 (4), 212-215.

Sedeaudab, A., Marca, A., Schipmana, J., Schaalc, K., Danialde, M., Guillaumea, M., Berthelotab, G, Toussaint, J.F. (2014). Secular trend: morphology and performance. Journal of Sports Sciences, 32 (12), 1146-1154.

Sitek, A., Szkudlarek, A., Antoszewski, B. (2007). Secular changes in the physical development of students of the Medical University of Łódź. Folia Morphologica, 66 (1), 62-68.

Stachoń, A., Burdukiewicz, A., Pietraszewska, J., Andrzejewska, J. (2012). Changes in Body Build of AWF Students 1967-2008. Can a Secular Trend be Observed? Human Movement, 13 (2), 109-119.

Sterkowicz-Przybycień, K. (2010). Technical diversification, body composition and somatotype of both heavy and light Polish ju-jitsukas of high level. Science \& Sports, 25, 194-200.

Tanner, J.M. (1987). Growth as a mirror of the condition of society, secular trends and class distinctions. Acta Paediatrica Japonica, 29, 96-103.

Tanner, J.M. (1992). Growth as a measure of the nutritional and hygienic status of a population. Hormone Research, 38 (suppl.1), $106-115$.

Tanner, J.M., Hayashi, T., Preece, M.A., Cameron, N. (1982). Increase in length of leg relative to trunk in Japanese children and adults from 1957 to 1977, comparison with British and with Japanese Americans. Annals of Human Biology, 9, 411-423.

Vidal Andreato, L., Franzói de Moraes, S.M., Lopes deMoraes Gomes, T., Del Conti Esteves, J.V., Vidal Andreato, T., Franchini, E. (2011). Estimated aerobic power, muscular strength and flexibility in elite Brazilian Jiu-Jitsu athletes. Science \& Sports, 26 (6), 329-337.

Ziółkowska-Łajp, E. (1999). Study in tendency of changes of morphological features - conditionings and effects in the light of long-term research [in Polish]. Monografie Akademii Wychowania Fizycznego w Poznaniu, 336.

Cite this article aS:" Pietraszewska, J., Burdukiewicz, A., Stachoń, A., Andrzejewska, J., Chromik, K. (2018). Long-term Changes in Body Build of Male and Female Judo Competitors. Central European Journal of Sport Sciences and Medicine, 2 (22), 69-77. DOI: 10.18276/cej.2018.2-08. 